\title{
Survival of Porcine Delipated Oocytes and Embryos after Cryopreservation by Freezing or Vitrification
}

\author{
Hiroshi NAGASHIMA\#, Ranald D. A. CAMERON1), Masashige KUWAYAMA ${ }^{2)}$, \\ Mary YOUNG ${ }^{1)}$, Luke BEEBE ${ }^{1)}$, Alan W. BLACKSHAW ${ }^{1)}$ and Mark B. NOTTLE
}

\author{
BresaGen Limited, PO Box 259, Rundle Mall, Adelaide, S.A. 5000, \\ 1) Department of Farm Animal Medicine and Production, \\ The University of Queensland, Queensland 4067, Australia, and \\ 2) Animal Biotechnology Center, Livestock Improvement Association, Shinagawa, \\ Tokyo 140-0002, Japan
}

\begin{abstract}
The present study examined whether delipated porcine oocytes and embryos at various stages of development can be cryopreserved by conventional slow cooling or vitrification. Most $(93 \%)$ of the 27 delipated morulae developed to blastocysts after freezing with $1.5 \mathrm{M}$ propanediol + $0.1 \mathrm{M}$ sucrose. Late morulae and early blastocysts delipated at 2-4 cell stage and cultured in vitro survived freezing either with $1.5 \mathrm{M}$ glycerol + 0.25 M sucrose $(10 / 18,56 \%)$ or $1.8 \mathrm{M}$ ethylene glycol $+0.25 \mathrm{M}$ sucrose (14/19,74\%). Delipated 2-4 cell stage embryos and oocytes could be cryopreserved by vitrification with $40 \%$ ethylene glycol, $1 \mathrm{M}$ sucrose and $20 \%$ fetal calf serum. Half $(7 / 14)$ of the vitrified, delipated embryos developed to blastocysts after thawing. Of 48 delipated oocytes, $27(56 \%)$ maintained an intact outline of the ooplasm after vitrification and underwent subzonal sperm injection. Fertilization was confirmed in $12(25 \%)$ of these oocytes and $3(6 \%)$ developed to morula stage. This study also aimed at developing a non-invasive method for cryopreserving porcine embryos after reducing their cytoplasmic lipid content without micromanipulation. Morulae and early blastocysts were centrifuged in the presence of cytochalasin B and cryoprotectants and then frozen immediately. More than half (14/24, 58\%) of the centrifuged morulae developed to blastocycts after freezing with $1.5 \mathrm{M}$ propanediol $+0.1 \mathrm{M}$ sucrose. Greater than $70 \%$ of centrifuged early blastocysts survived freezing either with $1.5 \mathrm{M}$ propanediol (30/31, $97 \%), 1.5 \mathrm{M}$ glycerol $(22 / 29,76 \%)$ or $1.8 \mathrm{M}$ ethylene glycol $(21 / 29,72 \%)$. These results demonstrated that delipation (lipid removal) from porcine oocytes and embryos at various stages enables their cryopreservation. A new insight into the development of a non-invasive method for cryopreserving porcine embryos was also provided.
\end{abstract}

Key words: Pig, Embryo, Oocyte, Cryopreservation, Vitrification, Delipation.

(J. Reprod. Dev. 45: 167-176, 1999)

S urvival of porcine embryos after cryopreservation in liquid nitrogen has been confined to embryos at the peri-hatching and late blastocyst

Accepted for publication: February 9, 1999

Correspondence: H. Nagashima

"Present address: Laboratory of Reproduction Engineering, Faculty of Agriculture, Meiji University, 1-1-1 Higashimita, Tama, Kawasaki 214-8571, Japan stage [1, 2, 4-6] with limited embryonic development after transfer [7-13]. The absence of effective embryo cryopreservation technologies may not only result in a major loss of genetic diversity in this species, but also hinder application of reproductive technologies (e.g., embryo transfer, in vitro fertilization, embryo cloning) to the pig industry. For these reasons, studies resulting in a better un- 
derstanding of the factors responsible for the high sensitivity of porcine embryos to cryopreservation is essential to further improvement of porcine embryo cryopreservation.

We have demonstrated that removal of cytoplasmic lipid droplets from the 2-4 cell stage porcine embryos dramatically increased their tolerance to freezing and live piglets could be produced using this method [3]. Thus the high sensitivity of porcine embryos to cryopreservation was ascribed to their high lipid content in the cytoplasm $[3,14]$.

In contrast to porcine embryos, mouse embryos which have a relatively low lipid content in their cytoplasm are known to be highly tolerant to cryopreservation [15, 16]. Mouse ova from 1-cell to blastocyst stage withstand cryopreservation using various cryoprotective agents, such as DMSO, 1,2propanediol, ethylene glycol and glycerol [15, 17-28], and various methods including slow cooling [15], ultra-rapid freezing [17] and vitrification [18].

In our previous study, delipated porcine embryos at the 2- to 8-cell stage were cryopreserved in the presence of $1.5 \mathrm{M}$ 1,2-propanediol (PROH) and $0.1 \mathrm{M}$ sucrose by a conventional slow cooling method [3]. However it is yet to be determined whether survival of delipated porcine embryos after cryopreservation with this method is confined to the 2-8 cell stage. Therefore, the objective of the present study was to investigate whether delipated porcine oocytes and embryos at various stages of development can be cryopreserved. Morulae were delipated and their cryo-tolerance tested by freezing with $\mathrm{PROH}$ and sucrose. Second, post-freezing survival of the morulae and early blastocysts delipated at the 2-4 cell stage and cultured in vitro was examined. Third, we examined whether the delipated 2-4-cell stage embryos which already had been shown to withstand freezing with $\mathrm{PROH}$ and sucrose can be vitrified. Delipated oocytes were also vitrified and their survival was evaluated by development after fertilization.

Removal of cytoplasmic lipid droplets from porcine embryos requires micromanipuation, and this is a setback for practical application of the embryo cryopreservation. Therefore, in additional series of experiments, we aimed at developing a non-invasive method for cryopreserving porcine embryos. Morula and early blastocyst stage embryos were centrifuged and frozen immediately to examine whether polarization of the cytoplasmic lipid drop- lets of these embryos render them less sensitive to cryoinjury.

\section{Materials and Methods}

\section{Collection of ova}

Thirty pregnant crossbred gilts (Large White $x$ Landrace) were used as embryo donors. Animals were aborted by intramuscular (i.m.) injection of 1 $\mathrm{mg}$ of a prostaglandin $\mathrm{F} 2 \alpha$ analogue (Cloprostenol; Estrumate, Pitman-Moore, New South Wales, Australia) between 25 to 40 days after the mating, followed by a second injection of $0.5 \mathrm{mg}$ Cloprostenol $24 \mathrm{~h}$ later. Seven-hundred and fifty i.u. (for embryo collection) or 1000 i.u. (for oocyte collection) of eCG (Pregnecol, Heriot AgVet, Victoria, Australia) was administrated (i.m.) at the same time as the second injection of Cloprostenol. Ovulation was induced by i.m. injection of 500 i.u. hCG (Chorulon, Intervet, New South Wales, Australia) administrated approximately $72 \mathrm{~h}$ after eCG. Oocytes were collected 48 to $52 \mathrm{~h}$ after hCG injection by surgically flushing both oviducts. Embryo donors were mated on the following afternoon (Day 0 ) of hCG injection with fertile Large White boars. Two- to four-cell, early compacting morula (8-16 cell) and early blastocyst stage embryos were surgically collected 72-76 h (day-2), 120-124 h (day-4) and 144-148 h (day-5) after the hCG injection, respectively.

\section{Oocyte and embryo culture}

Oocytes and embryos were cultured in $50 \mu \mathrm{l}$ droplets of Whitten's medium (WM) [29] supplemented with $15 \mathrm{mg} / \mathrm{ml}$ BSA (fraction V; Pentex, Miles, IL) under paraffin oil in a plastic Petri dish held under an atmosphere of $5 \% \mathrm{CO}_{2}, 5 \% \mathrm{O}_{2}$ and $90 \% \mathrm{~N}_{2}$ in humidified air at $38.6 \mathrm{C}$. Fetal calf serum $(5 \%$; FCS) was added to the culture of embryos at the morula or later stages.

Development of the embryos was observed every $24 \mathrm{~h}$ under a dissecting microscope at $\times 100$ magnification. A proportion of embryos were fixed with aceto-alcohol and stained with $1 \%$ aceto-orcein to examine nucleus number and/or fertilization.

\section{Removal of cytoplasmic lipid droplets from embryos}

Cytoplasmic lipid droplets of oocytes (Fig. 3a), 2-4 cell embryos (Fig. 2a) and morulae (Fig. 1a, b) were removed (delipated) by procedures described 


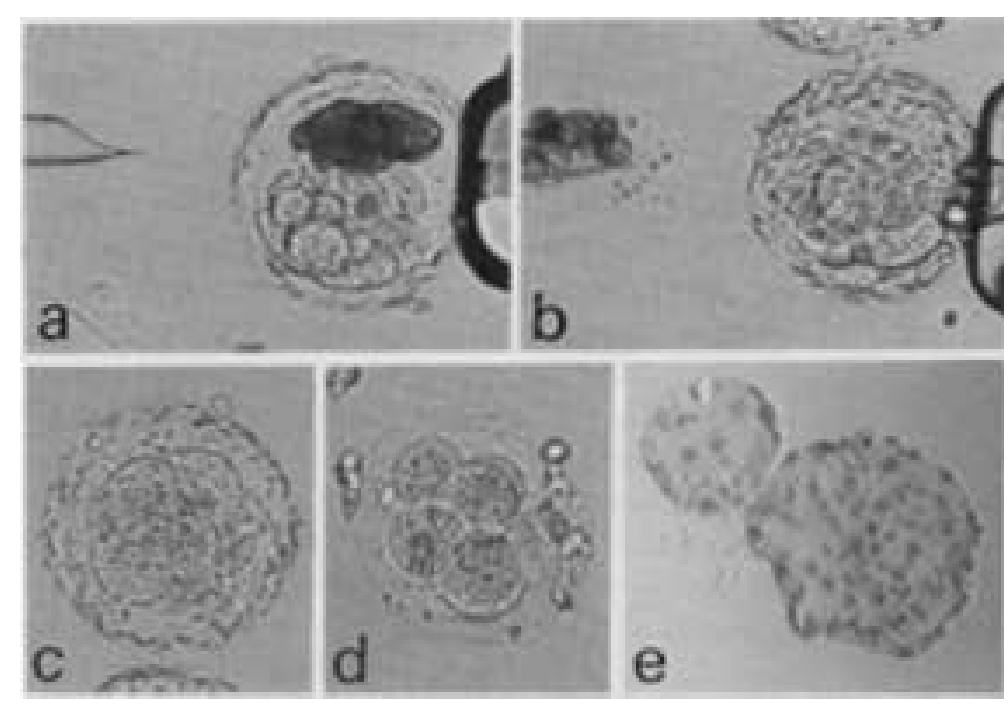

Fig. 1. Development of delipated porcine morulae after freezing with 1.5 $\mathrm{M}$ 1,2-propanediol and $0.1 \mathrm{M}$ sucrose.

A, B: A morula stage embryo after centrifugation to polarise the cytoplasmic lipid droplets (A) and after removal of the polarised lipid by micromanipulation (B). C, D: A delipated morula before (C) and after (D) freezing. E: A hatching blastocyst developed from delipated morula after freezing; fixed and stained $96 \mathrm{~h}$ after thawing. $\quad A-C=\times 200, D=\times 100$.

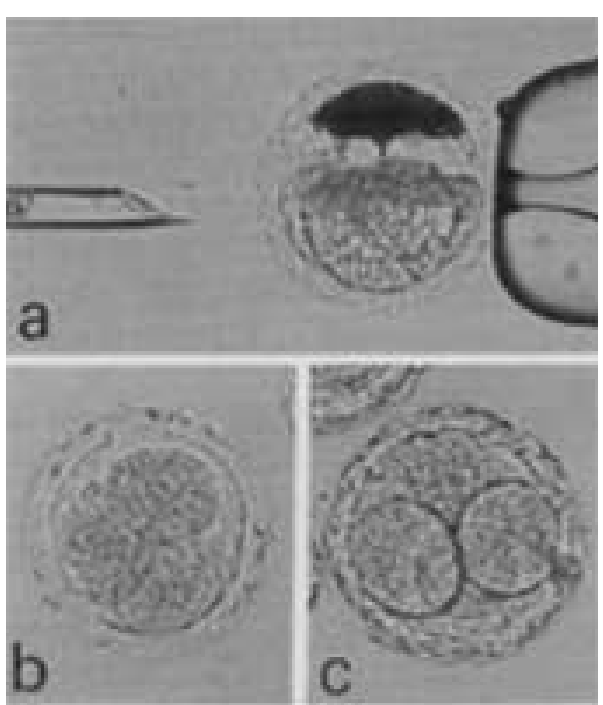

Fig. 2. Survival of delipated porcine 4-cell stage embryos after vitrification $(x$ 200).

A: A centrifuged 4-cell stage embryo with polarized lipid droplets. B, C: A delipated 4-cell stage embryo before (B) and after (C) the vitrification. previously $[3,14]$. Briefly, oocytes and embryos were centrifuged at $12500 \times \mathrm{g}$ for 15 and $10 \mathrm{~min}$, respectively, in 20-50 $\mu \mathrm{l}$ of modified Dulbecco's phosphate buffered saline (PB1) [30] containing 10 $\%$ FCS and $7.5 \mu \mathrm{g} / \mathrm{ml}$ cytochalasin B (CB; Cytochalasin B, Sigma, MO, USA) in $1.5 \mathrm{ml}$ microcentrifuge tubes (Micro-centrifuge test tube, Treff Lab, Schweiz, Switzerland) at room temperature to polarise the cytoplasmic lipid droplets. Oocytes were preincubated with $\mathrm{CB}$ for $10 \mathrm{~min}$ at $37 \mathrm{C}$ prior to the centrifugation. The resultant lipid layer was removed from oocytes and embryos by micromanipulation using a bevelled suction pipette (35-40 $\mu \mathrm{m}$ in outer diameter) attached to Narishige micromanipulators (MO-108; Tokyo, Japan) under a Nikon inverted microscope (TMD; Tokyo, Japan). After lipid-removal the oocytes and embryos were washed with PB1+10\% FCS and kept in the same medium or cultured as described above prior to freezing.

\section{Cryopreservation of oocytes and embryos}

Embryos and oocytes were cryopreserved by conventional slow cooling methods $[3,4]$ or vitrification [31]. Equilibration, freezing and rehydration

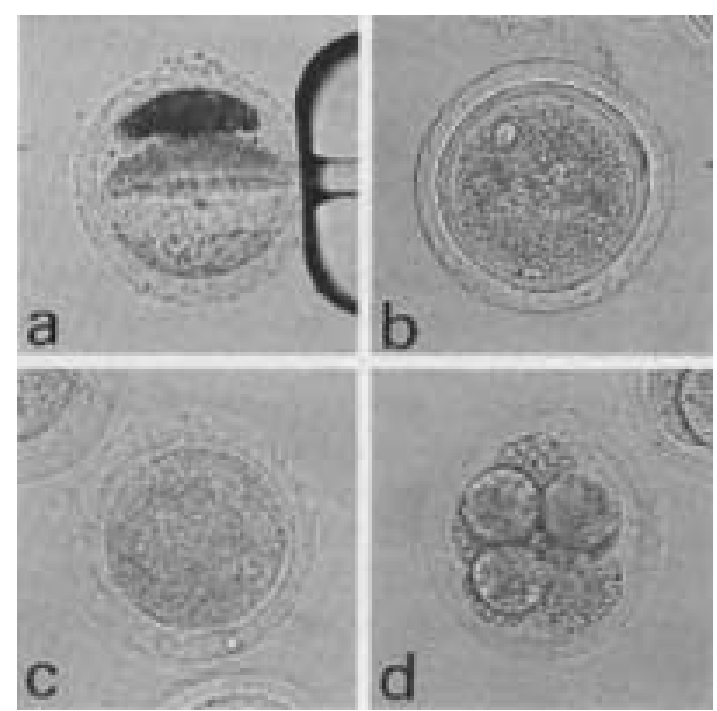

Fig. 3. Survival of porcine ovulated oocytes after vitrification $(\times 200)$.

A: An oocyte after centrifugation to polarise the cytoplasmic lipid droplets. B, C: A delipated oocyte before (B) and after $(\mathrm{C})$ vitrification. $\mathrm{D}$ : A 8-cell stage embryo developed from vitrified, delipated oocyte after SUZI. 
media for the slow cooling methods were prepared using PB1 $+10 \%$ FCS as the basic medium. Hepes (20 mM) buffered TCM 199 (basic-TCM) was used to prepare equilibration and vitrification media for the vitrification method. The oocytes and embryos were stored in liquid nitrogen for at least one week, except for the vitrified oocytes which were thawed after storage over night.

\section{Slow cooling method with 1,2-propanediol}

Embryos were equilibrated with $1.5 \mathrm{M}$ 1,2-propanediol (PROH) for $10 \mathrm{~min}$, and then loaded into a $0.25 \mathrm{ml}$ plastic straw with the freezing medium which consisted of $1.5 \mathrm{M}$ PROH and $0.1 \mathrm{M}$ sucrose in the basic medium. These were cooled directly from room temperature to $-6.5 \mathrm{C}$, seeded for 10 $\mathrm{min}$ and then cooled at a rate of $0.3 \mathrm{C} / \mathrm{min}$ to -30 $\mathrm{C}$ using a programmable freezer (Freeze Control, CryoLogic, Victoria, Australia) before plunging into liquid nitrogen. After thawing in a $30 \mathrm{C}$ water bath, the embryos were rehydrated by exposing them stepwise for $10 \mathrm{~min}$ to $0.75 \mathrm{M}$ PROH $+0.2 \mathrm{M}$ sucrose, for $5 \mathrm{~min}$ to $0.2 \mathrm{M}$ sucrose and for $10 \mathrm{~min}$ to PB1 $+10 \%$ FCS, and washed with the same medium two times.

Slow cooling method with glycerol or ethylene glycol

Embryos were held briefly (less than $1 \mathrm{~min}$ ) in freezing media consisting of $1.5 \mathrm{M}$ glycerol +0.25 M sucrose or 1.8 M ethylene glycol (EG) $+0.25 \mathrm{M}$ sucrose at room temperature, and then loaded into a $0.25 \mathrm{ml}$ plastic straw with the same media. Straws were frozen and thawed by the same manner as used for the freezing with propanediol. After thawing, the embryos were rehydrated by exposing them stepwise for $5 \mathrm{~min}$ to $0.75 \mathrm{M}$ glycerol $+0.3 \mathrm{M}$ sucrose or $0.9 \mathrm{M} \mathrm{EG}+0.3 \mathrm{M}$ sucrose, for $5 \mathrm{~min}$ to $0.3 \mathrm{M}$ sucrose and for $5 \mathrm{~min}$ to $0.15 \mathrm{M}$ sucrose, followed by washing with PB1+10\%FCS three times.

\section{Vitrification}

Embryos and oocytes were vitrified by the method of Kuwayama et al. [31]. The vitrification solution consisted of $40 \%$ ethylene glycol, $1 \mathrm{M}$ sucrose and 20\% FCS in basic-TCM. A $25 \mu \mathrm{l}$ column of vitrification medium was loaded in a $0.25 \mathrm{ml}$ plastic straw with an adjacent $175 \mu \mathrm{l}$ column of diluent consisting of $10 \%$ egg yolk, $0.5 \mathrm{M}$ sucrose and 20\% FCS in basic-TCM. During and after load- ing of solutions, straws were kept upright with the column of vitrification solution down, so that the both columns were kept separated due to a difference in density between the two solutions. Before loading into straws, the eggs were equilibrated with $10 \%$ glycerol for $10 \mathrm{~min}$ at room temperature $(25$ C). The eggs were transferred to the vitrification medium and loaded within 1 min into the column of vitrification medium using a finely drawn capillary pipette. After heat sealing the end, straws were plunged into liquid nitrogen. Straws were thawed by holding in room temperature air for 10 sec and in $37 \mathrm{C}$ water for $30 \mathrm{sec}$. After thawing, the straws were kept upright for $10 \mathrm{sec}$ with the columns of vitrification medium up, so that the eggs in the vitrification medium slowly moved down into the adjacent column of diluent. Contents of the straw was expelled in a Petri dish and the eggs were washed 5 times with basic-TCM + $20 \%$ FCS.

\section{Experiment 1. Freezing of delipated morulae}

The aim of this experiment was to examine whether porcine embryos at the morula stage could be cryopreserved after removal of their cytoplasmic lipid droplets by the same freezing method which had been shown to be effective for the delipated 2-8 cell stage embryos in our previous study [3]. Morula stage embryos (8-16 cell) were delipated and cultured in vitro prior to freezing for 2-4 $\mathrm{h}$ to allow them to recompact. Delipated morulae were frozen in the presence of $1.5 \mathrm{M} \mathrm{PROH}$ and $0.1 \mathrm{M}$ sucrose and their survival after thawing was assessed by culturing for $96 \mathrm{~h}$.

\section{Experiment 2. Freezing of morulae and early blastocysts developed in vitro from delipated embryos}

In this experiment, embryos were delipated at 2-4 cell stage and developed by culture for $92-96$ $\mathrm{h}$ to the late morula to early blastocyst stage. The aim was to investigate whether the cryo-tolerance of delipated embryos can be maintain after the in vitro development. Embryos were frozen in the presence of $1.5 \mathrm{M}$ glycerol $+0.25 \mathrm{M}$ sucrose or 1.8 $\mathrm{M}$ EG $+0.25 \mathrm{M}$ sucrose by the slow cooling method, and their survival after thawing was assessed by in vitro culture for $48 \mathrm{~h}$. 
Experiment 3. Vitrification of delipated 2-4 cell stage embryos

Delipated 2-4 cell stage embryos which had been shown in our previous study to survive cryopreservation by a conventional slow cooling method with $1.5 \mathrm{M} \mathrm{PROH}+0.1 \mathrm{M}$ sucrose [3] were vitrified and their survival after thawing was examined by culture for $120 \mathrm{~h}$. Centrifuged (not delipated) and intact control embryos at the identical stage as the delipated embryos were also vitrified.

\section{Experiment 4. Vitrification of delipated oocytes}

This experiment was conducted to examine whether the delipated porcine oocytes can be cryopreserved by vitrification. Delipated oocytes were vitrified within $1 \mathrm{~h}$ after micromanipulation. After thawing, survival of oocytes were assessed by fertilization and in vitro development following subzonal sperm injection (SUZI) using methods described previously $[32,33]$. Sperm were preincubated in $25 \mathrm{mM}$ Hepes buffered TCM199 (pH 7.8) supplemented with calcium lactate $(0.9 \mathrm{mg} /$ $\mathrm{ml}$ ) and $12 \%$ FCS for 30 to $60 \mathrm{~min}$ with a concentration of $4 \times 10^{8}$ cells $/ \mathrm{ml}$ at $38.5 \mathrm{C}$ in a humidified atmosphere of $5 \% \mathrm{CO}_{2}$ in air [33].

Oocytes were placed in a droplet $(10 \mu \mathrm{l})$ of PB1 $+10 \%$ FCS covered with paraffin oil in a plastic Petri dish. Sperm were resuspended in an adjacent droplet $(1 \mu \mathrm{l})$ to give a final concentration of approximately $1 \times 10^{5} \mathrm{cell} / \mathrm{ml}$.

A bevelled injection pipette $(10-15 \mu \mathrm{m}$ in outer diameter) attached to a Narishige micromanipulator (MO-108; Tokyo, Japan) was introduced into the droplet of sperm suspension and 20-50 sperm were aspirated under a Nikon inverted microscope (TMD; Tokyo, Japan). Three to five motile sperm were injected into the perivitelline space of an oocyte held by a holding pipette.

Sperm-injected oocytes were incubated for $5 \mathrm{~h}$ in $100 \mu$ droplets of TALP-PVA medium [34] supplemented with $2 \mathrm{mM}$ caffeine-sodium benzoate. Oocytes were then cultured in WM as described above. Oocytes which had not cleaved by $40 \mathrm{~h}$ after SUZI were fixed and stained to examine for fertilization. Oocytes which had cleaved by $40 \mathrm{~h}$ were cultured for a further 3 days to observe development.
Experiment-5. Freezing of morulae and early blastocysts following centrifugation

This experiment aimed at developing a non-invasive method for cryopreserving porcine embryos after reducing lipid content of their cytoplasm. Morulae and early blastocysts were centrifuged in the same manner as for the delipated embryos, except that the embryos were centrifuged in the presence of cryoprotectants together with $7.5 \mu \mathrm{g} /$ $\mathrm{ml} \mathrm{CB}$. Early blastocysts were centrifuged at 13400 $\times \mathrm{g}$ instead of $12500 \times \mathrm{g}$ for morulae.

Morulae were centrifuged with $1.5 \mathrm{M} \mathrm{PROH}$ and frozen with $1.5 \mathrm{M}$ PROH $+0.1 \mathrm{M}$ sucrose. Early blastocysts were centrifuged with $1.5 \mathrm{M} \mathrm{PROH}$, 1.8 M EG or $1.5 \mathrm{M}$ glycerol and frozen with $1.5 \mathrm{M}$ $\mathrm{PROH}+0.1 \mathrm{M}$ sucrose, $1.8 \mathrm{M} \mathrm{EG}+0.25 \mathrm{M}$ sucrose or 1.5 M glycerol + 0.25 M sucrose. After centrifugation the embryos were recovered and loaded into straws with the freezing medium within one minute and frozen-thawed in the same manner as in Experiments 1 (morulae) and 2 (early blastocysts). Post-thaw survival of the morulae and early blastocysts were evaluated in culture for 96 and 72 $h$, respectively, and cell numbers of the developing blastocysts counted.

Some of the early blastocysts were fixed and stained before the centrifugation / freezing to count the original cell numbers.

\section{Statistics}

At least 3 replicates were carried out in each experiment. Differences between groups in the developmental rates of cryopreserved embryos were analyzed by $\chi^{2}$ test with Yates' correction for independence. Student's t-test was used to compare mean cell numbers of embryos.

\section{Results}

Experiment-1. Survival of delipated morulae after freezing with $\mathrm{PROH}$

Of 27 delipated morulae (Fig. 1c) frozen with 1.5 $\mathrm{M} \mathrm{PROH}+0.1 \mathrm{M}$ sucrose, 17 (63.0\%) were recovered without any morphological sign of cell injury (Fig. 1d). Ten embryos were observed to have a few injured blastomeres at recovery. Nearly all $(25 / 27,92.6 \%)$ of the frozen-thawed embryos developed to the blastocyst stage including the hatching (Fig. 1e) and hatched stages after culture 
Table 1. Survival of porcine delipated morulae after freezing with 1,2-propanediol

\begin{tabular}{cccc}
\hline $\begin{array}{c}\text { No. of delipated } \\
\text { morulae frozen }\end{array}$ & $\begin{array}{c}\text { No. of embryos } \\
\text { developed to } \\
\text { blastocysts }\end{array}$ & $\begin{array}{c}\text { No. of embryos } \\
\text { developed beyond } \\
\text { hatching blastocysts }\end{array}$ & $\begin{array}{c}\text { Cell numbers } \\
\text { of blastocysts } \\
\text { (mean } \pm \text { S.E.) }\end{array}$ \\
\hline 27 & 25 & 17 & $100 \pm 8.3$ \\
\hline
\end{tabular}

Table 2. Survival of porcine delipated 2-4 cell embryos after vitrification

\begin{tabular}{lcccc}
\hline Embryos & $\begin{array}{c}\text { No. of embryos } \\
\text { vitrified }\end{array}$ & $\begin{array}{c}\text { No. of embryos } \\
\text { recovered }\end{array}$ & $\begin{array}{c}\text { No. of embryos } \\
\text { developed to } \\
\text { blastocyst stage }\end{array}$ & $\begin{array}{c}\text { Mean cell } \\
\text { numbers } \\
\text { of blastocysts }\end{array}$ \\
\hline $\begin{array}{l}\text { delipated } \\
\text { centrifuged }\end{array}$ & 17 & 14 & $7(50 \%)^{\mathrm{a}}$ & $42.9 \pm 12.3$ \\
control & 17 & 11 & $1(9 \%)^{\mathrm{a}}$ & 28 \\
\hline
\end{tabular}

a $\mathrm{P}<0.05$

for $96 \mathrm{~h}$ (Table 1). Cell numbers for these embryos ranged from 50 for blastocysts to 184 for hatching blastocysts.

Experiment 2. Survival of delipated, in vitro developed morulae and early blastocysts after freezing with glycerol or $E G$

Of 41 delipated $2-4$ cell stage embryos, 37 developed in vitro to late morula or early blastocyst stage when frozen in the presence of $1.5 \mathrm{M}$ glycerol + $0.25 \mathrm{M}$ sucrose or 1.8 M EG + 0.25 M sucrose. More than half of the embryos in both groups $(10 / 18$, $55.6 \%$ for glycerol and $14 / 19,73.7 \%$ for EG) survived freezing, and developed to expanding or hatching blastocysts after thawing. The developmental rates did not differ significantly between the two groups.

\section{Experiment 3. Survival of delipated 2-4 cell embryos after vitrification}

Of the 17 embryos vitrified in each of three groups (delipated, centrifuged and intact control), 3,6 and 7 embryos were not recovered from the straws after thawing, respectively. In some cases, small fragments of zona pellucida were found in the diluent recovered from the straws, suggesting that some of the missing embryos were destroyed during vitrification and/or thawing.

Post-thaw survival of the embryos were presented in Table 2. Nine (64.3\%) out of the 14 delipated embryos recovered maintained an equivalent morphology as they were before vitrification (Fig. 2-b, c), and $7(50.0 \%)$ developed to blastocysts. In con-
Table 3. Survival of porcine delipated oocytes after vitrification

\begin{tabular}{cccc}
\hline $\begin{array}{c}\text { No. of } \\
\text { oocytes } \\
\text { vitrified }\end{array}$ & $\begin{array}{c}\text { No. of } \\
\text { oocytes } \\
\text { sperm } \\
\text { injected }\end{array}$ & $\begin{array}{c}\text { No. of } \\
\text { oocytes } \\
\text { fertilized }\end{array}$ & $\begin{array}{c}\text { No. of } \\
\text { oocytes } \\
\text { developed }\end{array}$ \\
\hline 48 & $27(56.3 \%)$ & $12(25.0 \%)$ & $3(6.3 \%)$ \\
\hline
\end{tabular}

trast, only one $(1 / 11,9.1 \%)$ of the centrifuged embryos developed to the blastocyst stage. Blastocyst formation rate of the centrifuged embryos was significantly lower than that of the delipated embryos $(\mathrm{P}<0.05)$. None $(0 / 10)$ of the intact control embryos developed after vitrification.

\section{Experiment 4. Survival of delipated oocytes after vitrification}

Vitrified oocytes could be fertilized and develop in vitro to 8-cell through to early morula stage after SUZI (Table 3). Of 48 delipated oocytes, 27 $(56.3 \%)$ which had been recovered maintaining an apparently intact outline of the ooplasm were used for SUZI (Fig. 3 b, c). Twenty-four oocytes which had not cleaved by $40 \mathrm{~h}$ after the SUZI were fixed and stained. Fertilized sperm and/or male pronuclei were observed in 12 of these. Three oocytes which had cleaved by $40 \mathrm{~h}$ after the SUZI developed to 8-cell and early morula stage (Fig. 3d) and had 7, 8 and 12 nuclei, respectively, after culture for a further 3 days. 
Experiment-5. Survival of morulae and early blastocysts frozen after centrifugation

A large part of the polarised lipid droplets remained outside of the cytoplasm at thawing in most of morulae and early blastocysts. These lipid droplets tended to disperse in the perivitelline space during freeze-thawing. It was also observed that the hemisphere of the centrifuged embryos contiguous to the polarised lipids tended to be darker in colour than the distal hemisphere, indicating that the lipid droplets had redistributed to some extent into the cells of the centrifuged embryos during freezing and/or thawing.

More than half of the centrifuged morulae frozen with $1.5 \mathrm{M}$ PROH $+0.1 \mathrm{M}$ sucrose developed after thawing to blastocysts (58.3\%, Table 4 ) with the cell numbers ranging between 21 and 49 (Fig. 4a).

Many of the centrifuged early blastocysts (72.4$96.8 \%$, Table 5) re-blastulated after freezing in all the three cryoprotectants tested. More than half of the surviving embryos frozen with PROH and EG developed to the expanded or hatching blastocyst stage (Fig. 4b). Overall, embryos frozen with PROH had a significantly $(\mathrm{P}<0.05)$ higher survival (re-blasturation) rate, developmental rate and cell numbers in developing blastocysts compared with the other two groups frozen with EG and glycerol. Average cell number of the ealy blastocysts before the centrifugation and freezing was $31.8 \pm 1.3(\mathrm{n}=5)$.

Table 4. Survival of porcine morulae frozen following centrifugation

\begin{tabular}{cccc}
\hline $\begin{array}{c}\text { No. of } \\
\text { embryos } \\
\text { frozen }\end{array}$ & $\begin{array}{c}\text { No. of } \\
\text { embryos } \\
\text { recovered } \\
\text { and cultured }\end{array}$ & $\begin{array}{c}\text { No. of embryos } \\
\text { developed to } \\
\text { blastocysts }\end{array}$ & $\begin{array}{c}\text { Cell numbers } \\
\text { in blastocysts } \\
\text { (mean } \pm \text { S.E.) }\end{array}$ \\
\hline 25 & 24 & $14(58.3 \%)$ & $31.8 \pm 2.4$ \\
\hline
\end{tabular}

\section{Discussion}

The present study demonstrated that porcine morulae with 8-16 cells can be delipated by the same method developed for 1- and 2-4 cell stage embryos [3,14]. The polarised lipid mass formed after centrifugation appeared to consist of 8 to 16 similar sized segments. All individual blastomeres of morulae turned light in color after centrifugation. Together these findings indicate that the cytoplasmic lipid droplets in all the blastomeres were extruded out by the centrifugation.

Developmental rate of the delipated morulae to blastocysts after freezing was improved (93\% vs 31-64\%) compared with that of delipated embryos frozen at 2-8 cell stages in our earlier work [3].

This suggests that the morula stage may be more suitable for cryopreservation following delipation.

Morulae and early blastocysts delipated at 2-4 cell stage and cultured in vitro could survive cryopreservation either with glycerol or EG. The

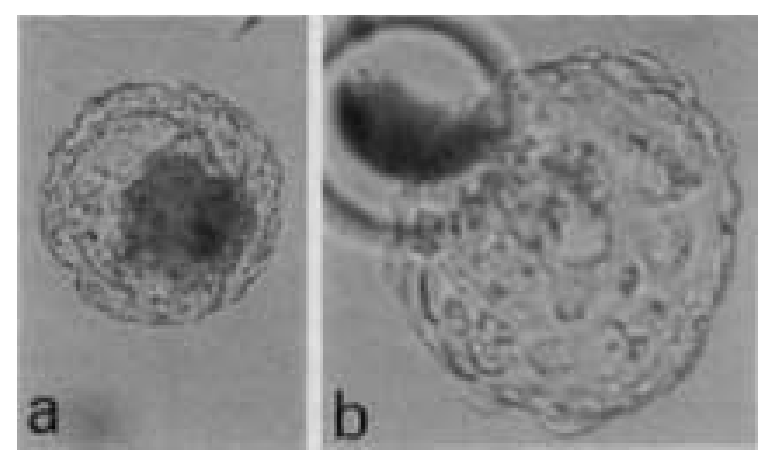

Fig. 4. Survival of porcine morulae and early blastocysts frozen after centrifugation $(\times 200)$. A centrifuged morula (A) and early blastocyst (B) which developed to blastocyst and hatching blastocyst stage, respectively, after freezing with $1.5 \mathrm{M}$ 1,2-propanediol and $0.1 \mathrm{M}$ sucrose; $48 \mathrm{~h}$ after thawing.

Table 5. Survival of porcine early blastocysts frozen following centrifugation

\begin{tabular}{ccccc}
\hline Cryoprotectants & $\begin{array}{c}\text { No. of embryos } \\
\text { frozen-thawed }\end{array}$ & $\begin{array}{c}\text { No. of embryos } \\
\text { re-blastulated }\end{array}$ & $\begin{array}{c}\text { No. of embryos } \\
\text { developed to >expanding } \\
\text { blastocyst stage }\end{array}$ & $\begin{array}{c}\text { Cell numbers } \\
\text { in blastocysts } \\
\text { (mean } \pm \text { S.E.) }\end{array}$ \\
\hline PROH & 31 & $30(96.8)^{\mathrm{a}}$ & $19(61.3)^{\mathrm{d}}$ & $66.1 \pm 6.4^{\mathrm{a}}$ \\
Glycerol & 29 & $22(75.9)^{\mathrm{b}}$ & $8(27.6)^{\mathrm{e}}$ & $44.7 \pm 6.7^{\mathrm{b}}$ \\
EG & 29 & $21(72.4)^{\mathrm{c}}$ & $13(44.8)^{\mathrm{f}}$ & $45.1 \pm 3.3^{\mathrm{b}}$ \\
\hline
\end{tabular}

ab $\mathrm{P}<0.05$, ac, de, $\mathrm{P}<0.01, \mathrm{bc}$, df, ef, non significant 
cryo-tolerance of these embryos is unlikely to be attributable to the effect(s) of culture prior to freezing, because in vitro development from 2-4 cell to morula/early blastocyst stage in our culture medium does not render cryo-tolerance to porcine embryos (unpublished data). Cytoplasm of the delipated embryos was observed to remain light in color throughout the culture period, suggesting that re-accumulation of the cytoplasmic lipid did not occur or was very limited. Therefore it was thought that the cryo-tolerance gained by delipation at the 2-4 cell stage was maintained after in vitro culture for 4 days.

The present study also demonstrated that vitrification is effective for cryopreserving delipated embryos. The vitrification method used in this study has been shown to be effective for cryopreserving undelipated porcine blastocysts [31]. However, vitrification of the embryos at morula or earlier stages resulted in very limited or no survival [31], suggesting that survival of the delipated embryos in this study can not be ascribed to the vitrification.

It was also shown that the delipated porcine oocytes can be cryopreserved by vitrification. To our knowledge, this is the first report on the successful development of porcine ovulated oocytes after the cryopreservation in liquid nitrogen, though both the fertilization $(25 \%)$ and developmental rates $(6 \%)$ of the vitrified oocytes were inferior to those of the non-cryopreserved oocytes after SUZI (61 and 42\%) observed in our previous study [32].

Damage of microtubles and microfilaments has been thought to be the major cause of loss or decrease of viability of oocytes after cryopreservation [35-37]. Cryo-injury to these elements is affected by the cryopreservation methods and cryoprotective agents used [35-37]. Therefore, optimization of the vitrification method may be necessary to improve the post-thaw survival of the delipated oocytes.

Recently, Vajta et al. reported that bovine oocytes [38] and porcine pre-morula stage embryos [39] could survive vitrification by the open straw method which was assumed to increase the speed of cooling and allow superior vitrified states compared with previous methods. This suggests that new methods may overcome the difficulty in cryopreserving porcine delipated oocytes.

In our previous study, it was shown that the 1to -4 cell stage embryos which had been centri- fuged but not delipated were not as tolerant as delipated embryos [14, 40]. It was hypothesised that lipid droplets polarised outside the blastomeres by centrifugation tended to redistribute throughout the cytoplasm during the process of the cryopreservation and therefore cryo-injury caused by the presence of cytoplasmic lipid droplets could not be eliminated. In contrast, the results of this study indicated that embryos at morula or early blastocyst stage could be successfully cryopreserved by freezing immediately after centrifugation. However, the increase of cell numbers in those embryos after thawing was limited, indicating that many of the blastomeres were damaged. The polarised lipid droplets left unremoved in the perivitelline space of the centrifuged morulae and blastocysts were observed to redistribute into the blastomeres, particularly those locating in the contiguous hemisphere to the polarised lipids. This implies that the embryos were incompletely delipated, and may not have been rendered fully cryo-tolerant [14]. A method to keep the cytoplasmic lipid droplets out of all the embryonic cells throughout the process of freeze-thawing may therefore be necessary to cryopreserve the porcine embryos after centrifugation. Cryopreservation method such as vitrification or ultra-rapid freezing would be effective for preventing redistribution of the polarised lipid droplets into the cytoplasm [41], hence would increase the post-thaw survival of the centrifuged embryos.

Porcine morulae and blastocysts having half the normal cell number after embryo-splitting have been shown to be competent to develop to normal offspring $[42,43]$. On the basis of this observation, porcine morulae and blastocysts cryopreserved after centrifugation are likely to maintain their viability, provided that the proportion of damaged cells does not exceed the half. Transfer experiments of the centrifuged-cryopreserved embryos are being conducted now.

In conclusion, the present study demonstrated that the porcine oocytes and embryos at various stages including 2-4 cell, morula and early blastocyst can be cryopreserved after removal of their cytoplasmic lipid droplets. Various cryoprotectants including $\mathrm{PROH}$, glycerol and EG, and both the slow cooling method and vitrification were shown to be effective in cryopreserving the delipated porcine embryos. These results also provide new insights into the development of a non-invasive 
method for cryopreserving porcine embryos.

\section{Acknowledgements}

This study was supported by a grant from the
Australian Research Council. The authors grateffuly acknowledge the support of Northfield Pig Research Unit, SARDI, South Australia.

\section{References}

1. Nagashima $\mathbf{H}$, Kato $\mathbf{Y}$, Yamakawa $H$, Matsumoto $\mathrm{T}$, Ogawa S. Changes in freezing tolerance of pig blastocysts in peri-hatching stage. Jpn J Anim Reprod 1989; 35: 130-134.

2. Nagashima $H$, Yamakawa $H$, Niemann $H$. Freezability of porcine blastocysts at different perihatching stages. Theriogenology 1992; 37: 839-850.

3. Nagashima $\mathbf{H}$, Kashiwazaki N, Ashman $\mathbf{R}$, Grupen CG, Nottle MB. Cryopreservation of porcine embryos. Nature 1995; 374: 416.

4. Kashiwazaki N, Nagashima H, Ashman RJ, Grupen CG, Nottle MB. Cryopreservation of porcine in vivo and in vitro derived blastocysts with glycerol or ethylene glycol. J Reprod Dev 1996; 42: 193-197.

5. Dobrinsky JR, Johnson LA. Development of porcine embryos cryopreserved by vitrification. In: Proceedings of 4th International Conference on Pig Reproduction; 1998; Columbia, USA. Abstruct 35.

6. Nagashima H, Kashiwazaki N, Ashman RJ, Grupen CG, Seamark RF, Nottle MB. Recent advances in cryopreservation of porcine embryos. Theriogenology 1994; 41: 113-118.

7. Kashiwazaki N, Ohtani S, Nagashima $H$, Yamakawa H, Cheng WTK, Lin A-T, Ma RC-S, Ogawa S. Production of normal piglets from hatched blastocysts frozen at $-196 \mathrm{C}$. Theriogenology 1991; 35: 221.

8. Nagashima H, Kashiwazaki N, Ashman RJ, Nottle MB. Improved survival of porcine hatched blastocysts cryopreserved with glycerol and sucrose. J Reprod Dev 1995; 41: 165-170.

9. Modl J, Reichenbach HD, Wolf E, Brem G. Development of frozen-thawed porcine blastocysts in vitro and in vivo. Vet Rec 1996; 139: 208-210.

10. Kuo Y-H. Study of frozen pig embryos and its transplantation. J Agric Assoc China 1993; New Series No.163: 82-92.

11. Fujino Y, Ujisato Y, Endo K, Tomizuka T, Kojima $\mathrm{T}$, Oguri N. Cryoprotective effect of egg yolk in cryopreservation of porcine embryos. Cryobiology 1993; 30: 299-305.

12. Dobrinsky JR, Pursel VG, Long CR, Johnson LA. Birth of normal piglets after cytoskeletal stabilization of embryos and cryopreservation by vitrification. Theriogenology 1998; 49: 166.
13. Kameyama K, Kudoh O, Takedomi T, Fukawa K. Transfer of cryopreserved pig embryos. Theriogenology 1997; 47: 366.

14. Nagashima H, Kashiwazaki N, Ashman RJ, Grupen CG, Seamark RF, Nottle MB. Removal of cytoplasmic lipid enhances the tolerance of porcine embryos to chilling. Biol Reprod 1994; 51: 618-622.

15. Whittingham DG. Survival of mouse embryos after freezing and thawing. Nature 1971; 233: 125-126.

16. Wood MJ, Whittingham DG, William FR. The low temperature preservation of mouse oocytes and embryos. In: Monk M (eds.), Mammalian development. Oxford, England: IRL Press; 1987: 255-280.

17. Trounson A, Peura A, Kirby C. Ultrarapid freezing; a new low-cost and effective method of cryopreservation. Fertil Steril 1987; 48: 843-850.

18. Rall WF, Fahy GM. Ice-free cryopreservation of mouse embryos at $-196 \mathrm{C}$ by vitrification. Nature 1985; 313: 573-574.

19. Shaw JM, Ward C, Trounson AO. Evaluation of propanediol, ethylene glycol, sucrose and antifreeze proteins on the survival of slow-cooled mouse pronuclear and 4-cell embryos. Hum Reprod 1995; 10: 396-402.

20. Kasai M, Komi JH, Takakamo A, Tsudera H, Sakurai T, Machida T. A simple method for mouse embryo cryopreservation in a low toxicity vitrification solution, without appreciable loss of viability. J Reprod Fertil 1990; 89: 91-97.

21. Nakagata $\mathbf{N}$. Cryopreservation of unfertilized mouse oocytes from inbred strains by ultrarapid freezing. Exp Anim 1990; 39: 303-305.

22. Rall WF, Wood MJ. High in vitro and in vivo survival of day 3 mouse embryos vitrified or frozen in a non-toxic solution of glycerol and albumin. $J$ Reprod Fert 1994; 101: 681-688.

23. Valdes CA, Abas-Mazni O, Takahashi Y, Fujikawa S, Kanagawa H. Successful cryopreservation of mouse blastocysts using a new vitrification solution. J Reprod Fertil 1992; 96: 793802.

24. Shaw PW, Fuller BJ, Bernard A, Shaw RW. Vitrification of mouse oocytes: Improved rates of survival, fertilization, and development to blastocysts. Mol Reprod Dev 1991; 29: 373-378. 
25. Shaw JM, Diotallevi L, Trounson AO. A simple rapid 4.5 $\mathrm{M}$ dimethyl-sulfoxide freezing technique for the cryopreservation of one-cell to blastocyst stage preimplantation mouse embryos. Reprod Fertil Dev 1991; 3: 621-626.

26. Nakagata N. Survival of mouse morulae and blastocysts derived from in vitro fertilization after ultra rapid freezing. Exp Anim 1993; 42: 229-231.

27. Szell A, Shelton JN. Osmotic and cryoprotective effects of glycerol-sucrose solutions on day-3 mouse embryos. J Reprod Fertil 1987; 80: 309-316.

28. Szell A, Shelton JN. Sucrose dilution of glycerol from mouse embryos frozen rapidly in liquid nitrogen. J Rreprod Fertil 1986; 76: 401-408.

29. Whitten WK. Nutrient requirements for the culture of preimplantation embryos in vitro. In: Raspé G (eds.), Advances in The Biosciences. Oxford: Pergamon Press; 1971: 129-141.

30. Quinn P, Barros C, Whittingham DG. Preservation of hamster oocytes to assay the fertilizing capacity of human spermatozoa. J Reprod Fert 1982; 66: 161-168.

31. Kuwayama M, Holm P, Jacobsen H, Greve T, Callesen H. Successful cryopreservation of porcine embryos by vitrification. Vet Rec 1997; 4: 365.

32. Nagashima H, Grupen CG, Ashman RJ, Nottle MB. Developmental competence of in vivo and in vitro matured porcine oocytes after subzonal sperm injection. Mol Reprod Dev 1996; 45: 359-363.

33. Grupen CG, Nagashima H, Nottle MB. Cysteamine enhances in vitro development of in vitro matured and fertilized porcine oocytes. Biol Reprod 1995; 53: 173-178.

34. Bavister BD. A consistently successful procedure for in vitro fertilization of golden hamster eggs. $\mathrm{G} a-$ mete Res 1989; 23: 139-158.

35. Vincent C, Pickering SJ, Johnson MH, Quick SJ.
Dimethylsulfoxide affects the organisation of microfilaments in the mouse oocytes. Mol Reprod Dev 1990; 26: 227-235.

36. Baka SG, Toth TL, Veeck LL, Jones HWJ, Muasher SJ, Lanzendorf SE. Evaluation of the spindle apparatus of in vitro matured human oocytes following cryopreservation. Hum Reprod 1995; 10: 1816-1820.

37. Aigner S, Van-der-Elst J, Siebzehnrubl E, Wildt $\mathbf{L}$, Lang $\mathbf{N}$. The influence of slow and ultra-rapid freezing on the organization of the meiotic spindle of the mouse oocyte. Hum Reprod 1992; 7: 857-864.

38. Vajta G, Booth PJ, Holm P, Greve T, Callesen H. Successful vitrification of early stage bovine in vitro produced embryos with the open pulled straw (OPS) method. Cryo-Let 1997; 18: 191-195.

39. Vajta G, Holm P, Greve T, Callesen H. Vitrification of porcine embryos using open pulled straw method. Acta Vet Scand 1997; 38: 349-352.

40. Nagashima H, Kashiwazaki N, Ashman RJ, Nottle MB. Successful cryopreservation of porcine early cleavage stage embryos following removal of cytoplasmic lipid. Theriogenology 1995; 43: 285.

41. Nagashima H, Kuwayama M, Grupen CG, Ashman RJ, Nottle MB. Vitrification of porcine early cleavage stage embryos and oocytes after removal of cytoplasmic lipid droplets. Theriogenology 1996; 45: 180.

42. Nagashima H, Kato $\mathbf{Y}$, Ogawa S. Microsurgical bisection of porcine morulae and blastocysts to produce monozygotic twin pregnancy. Gamete Res 1989; 23: 1-9.

43. Nagashima H, Katoh Y, Shibata K, Ogawa S. Production of normal piglets from microsurgically split morulae and blastocysts. Theriogenology 1988; 29: 485-495. 